\title{
Conversion of Tobacco Biomass to Flavor Components by Means of Microwave and Parr Reactors *
}

\author{
by \\ Katayoun Mahdavi Ara ${ }^{1}$, Larry T. Taylor ${ }^{1}$, and William. M. Coleman III ${ }^{2}$ \\ 1 Department of Chemistry, Virginia Tech, Blacksburg, VA 24061-0212, USA \\ 2 iii Consulting, LLC, 210 Jessamine Street, Conway, SC 29626, USA
}

\section{SUMMARY}

In the present work, microwave and Parr reactors were utilized for synthesis of pyrazines from plant-based biomass in the presence of ammonia and different amino acids. Using these techniques led to synthesis of a relatively wide range of pyrazines with sweet odor and chocolate-like smell. The optimum synthetic conditions to have maximum pyrazine yield for both the microwave and Parr reactions were $41 \mathrm{~g}$ of fructose/glucose syrup derived from cellulosic biomass, $28 \mathrm{~mL} \mathrm{NH}_{4} \mathrm{OH}(30 \%)$, and $0.96 \mathrm{~g} \mathrm{~L}$-threonine, $0.56 \mathrm{~g} \mathrm{~L}$-valine, $0.5 \mathrm{~g}$ L-leucine, and $0.5 \mathrm{~g} \mathrm{~L}$-isoleucine at $120{ }^{\circ} \mathrm{C}$ for $30 \mathrm{~min}$. Quantitative results obtained via gas chromatography-mass spectrometry (GC-MS) using the traditional open-heated oil bath method have been compared with data obtained via microwave and Parr reactors. In these two latter methods, sealed vessels under high pressure and higher temperature were used. The yield of synthesized pyrazines increased dramatically with both microwave and Parr reactors. Surprisingly, the yield of synthesized pyrazines was both reproducible and nearly two times higher via the Parr reactor than that observed with the microwave reactor under comparable conditions. [Beitr. Tabakforsch. Int. 27 (2017) 102-112]

KEY WORDS: Cellulosic glucose/fructose; alkylpyrazines; Parr and microwave; amino acids; "sludge"

\section{ZUSAMMENFASSUNG}

In der vorliegenden Arbeit wurden Mikrowellen- und ParrReaktoren zur Synthese von Pyrazinen aus Biomasse auf Pflanzenbasis in Gegenwart von Ammoniak und verschiedenen Aminosäuren eingesetzt. Mit diesen Verfahren gelang die Synthese einer relativ breiten Palette von Pyrazinen mit süßem Duft und schokoladen-ähnlichem Geruch. Die optimalen synthetischen Bedingungen für eine maximale Pyrazin-Ausbeute waren sowohl bei Mikrowellen- als auch Parr-Reaktionen 41 g Fruktose-/Glukose-Sirup aus zellulosehaltiger Biomasse, $28 \mathrm{~mL} \mathrm{NH}_{4} \mathrm{OH}(30 \%)$ und 0,96 g L-Threonin, 0,56 g L-Valin, 0,5 g L-Leucin und $0,5 \mathrm{~g}$ Isoleucin bei $120{ }^{\circ} \mathrm{C}$ für $30 \mathrm{~min}$. Mittels Gaschromatographie/Massenspektrometrie (GC-MS) und der herkömmlichen offen beheizten Ölbad-Methode erhaltene quantitative Ergebnisse wurden mit Daten aus Mikrowellen- und Parr-Reaktoren verglichen. In den letztgenannten zwei Methoden wurden verschlossene Gefäße unter hohem Druck und eine höhere Temperatur verwendet. Die Ausbeute der synthetisierten Pyrazine war sowohl in Mikrowellen- als auch in Parr-Reaktoren deutlich höher. Erstaunlicherweise war die Ausbeute synthetisierter Pyrazine sowohl reproduzierbar als auch fast zwei Mal höher mit dem Parr-Reaktor als unter vergleichbaren Bedingungen mit dem Mikrowellen-Reaktor. [Beitr. Tabakforsch. Int. 27 (2017) 102-112] 


\section{RESUME}

Dans le présent projet, nous avons utilisé des réacteurs Parr et à micro-ondes pour la synthèse des pyrazines à partir de biomasse d'origine végétale mise en présence d'ammoniaque et de différents acides aminés. Ces technologies nous ont permis de synthétiser un éventail relativement vaste de pyrazines à l'odeur fétide et au parfum rappelant le chocolat. Les conditions de synthèse optimales, requises pour un rendement maximal de pyrazines tant dans le réacteur Parr et que dans le réacteur micro-ondes, furent $41 \mathrm{~g}$ de sirop de fructose/glucose extrait de la biomasse cellulosique, $28 \mathrm{~mL}$ de $\mathrm{NH}_{4} \mathrm{OH}(30 \%)$ et $0,96 \mathrm{~g}$ de Lthréonine, $0,56 \mathrm{~g}$ de L-valine, $0,5 \mathrm{~g}$ de L-leucine et $0,5 \mathrm{~g}$ d'isoleucine portés à $120^{\circ} \mathrm{C}$ durant $30 \mathrm{~min}$. Les résultats obtenus grâce à la chromatographie en phase gazeuse couplée à la spectrométrie de masse (GC-MS) et à la méthode traditionnelle du bain d'huile chauffé et ouvert ont été comparés avec les données livrées par les réacteurs Parr et à micro-ondes. Pour ces deux dernières méthodes, des récipients scellés sous haute pression et portés à une plus haute température ont été employés. Le rendement des pyrazines synthétisées a augmenté de façon spectaculaire tant dans le réacteur Parr que dans le réacteur à microondes. A notre grande surprise, le rendement des pyrazines synthétisées s'est avéré à la fois reproductible et presque deux fois plus élevé au sein du réacteur Parr que le rendement observé dans le réacteur à micro-ondes, toutes conditions comparables. [Beitr. Tabakforsch. Int. 27 (2017) 102-112]

\section{INTRODUCTION}

Microwave radiation has been widely used as a powerful and controllable heating source for both organic and inorganic reactions since there is an immense increase in reaction speed under microwave radiation as compared with conventional heating. Apart from this main advantage, significant improvements in yield and selectivity have been observed as a consequence of the fast and direct heating of the reactants $(1)$. The main advantages $(2,3)$ of microwaveassisted organic synthesis compared to heated bath are: 1) Reactions are completed in a few minutes instead of hours; 2) Better product yield and higher purity are observed; 3) Scale-up from milliliters to liters without changing reaction parameters is straightforward; 4) Control of temperature, pressure, and power affords the same reaction conditions; 5) Reactions that involve conventional and microwave heating $(4,5)$ can be readily compared.

The short reaction times and expanded reaction parameters that are offered by microwave assisted-organic synthesis are well-suited for the increased production demands in industry. The advantages of microwave energy in the performance of organic reactions can be used for example in the synthesis of aqueous pyrazine formulations that are major flavor components in food and cigarettes (6). In this regard, two other alternative methods can be utilized to generate aqueous formulations of pyrazines. As an example, a Parr reactor incorporates a sealed vessel under pressure at selected temperatures. In another example, open vessels at ambient pressure have been used by several of the authors concerning pyrazine synthesis (7). The main disadvantages in the open vessels were limitations in the number of samples, temperature/pressure control, little variation in vessel dimensions, and replication of chemical syntheses.

In the present study, pyrazines with relatively short $(\mathrm{C} 1)$ and relatively long (C6) alkyl chains were synthesized using sealed vessels. Heat treatment of aqueous samples or suspensions was conducted in either specially designed vessels employing microwave conditions or in sealed, stirred, stainless steel heated reactors. The larger scale synthesis $(>200 \mathrm{~mL})$ and more widely variable synthetic conditions of Parr and microwave reactors afforded broader temperature capabilities, and resulted in an increased pyrazine yield relative to open heated vessels. These conditions unfortunately gave rise to an undesirable byproduct, which challenged our ability to eliminate it from the more desirable pyrazine product. This material, which was produced only under certain conditions, was labelled "sludge". When it appeared, it was observed near the bottom of the reactor vessel (microwave and Parr) as either an intractable dark brown refractory solid which had limited solubility in polar as well as nonpolar solvents or as a "gummy" substance which stuck to the walls and bottom of the reactor vessel. In many cases, removal of the "sludge" from the reaction vessel required mechanical scraping since polar solvents such as methanol or acetone were not effective. To address the "sludge" problem, determination of the optimum conditions for the reaction minus "sludge" was critical.

\section{MATERIALS AND METHODS}

\section{Chemicals and reagents}

Ammonium hydroxide (28-30\%), L-leucine, L-isoleucine, L-threonine, L-valine, dichloromethane, 2-methylpyrazine$\mathrm{d}_{6}$ (internal standard), and sodium sulfate were obtained from Sigma-Aldrich (St. Louis, MO, USA). Cellulosic glucose/fructose-A (CGF-A) (consists of $28 \%$ fructose and $33 \%$ glucose) and cellulosic glucose/fructose-B (CGF-B) (consists of $42 \%$ fructose and $50 \%$ glucose) from different plant sources were obtained from R.J. Reynolds Tobacco Co. (Winston-Salem, NC, USA).

\section{Instrumentation}

All GC/MS analyses were performed using a 6890 Gas Chromatograph equipped with a 5973 Mass Selective Detector (MSD) operating in the SCAN mode at $70 \mathrm{eV}$ from Agilent (Wilmington, DE, USA). Chromatographic separations were obtained using a DB-WAXTER capillary column $(30 \mathrm{~m}$ long $\times 250 \mu \mathrm{m}$ I.D. with a film thickness of $0.25 \mu \mathrm{m}$ ) from J\&W (Wilmington, DE, USA). The oven temperature was programmed $50{ }^{\circ} \mathrm{C}$ for $3 \mathrm{~min}$, then increased by $15{ }^{\circ} \mathrm{C} / \mathrm{min}$ from 50 to $240{ }^{\circ} \mathrm{C}$ and held for $3 \mathrm{~min}$. Helium was used as the carrier gas at a flow rate of $3 \mathrm{~mL} / \mathrm{min}$. Split ratio was adjusted at $1 / 25$. Mass spectra were obtained by electron impact ionization with an ionizing voltage of $70 \mathrm{eV}$ and an ionizing current of $150 \mathrm{~A}$. Synthesized pyrazines were identified by comparing their 

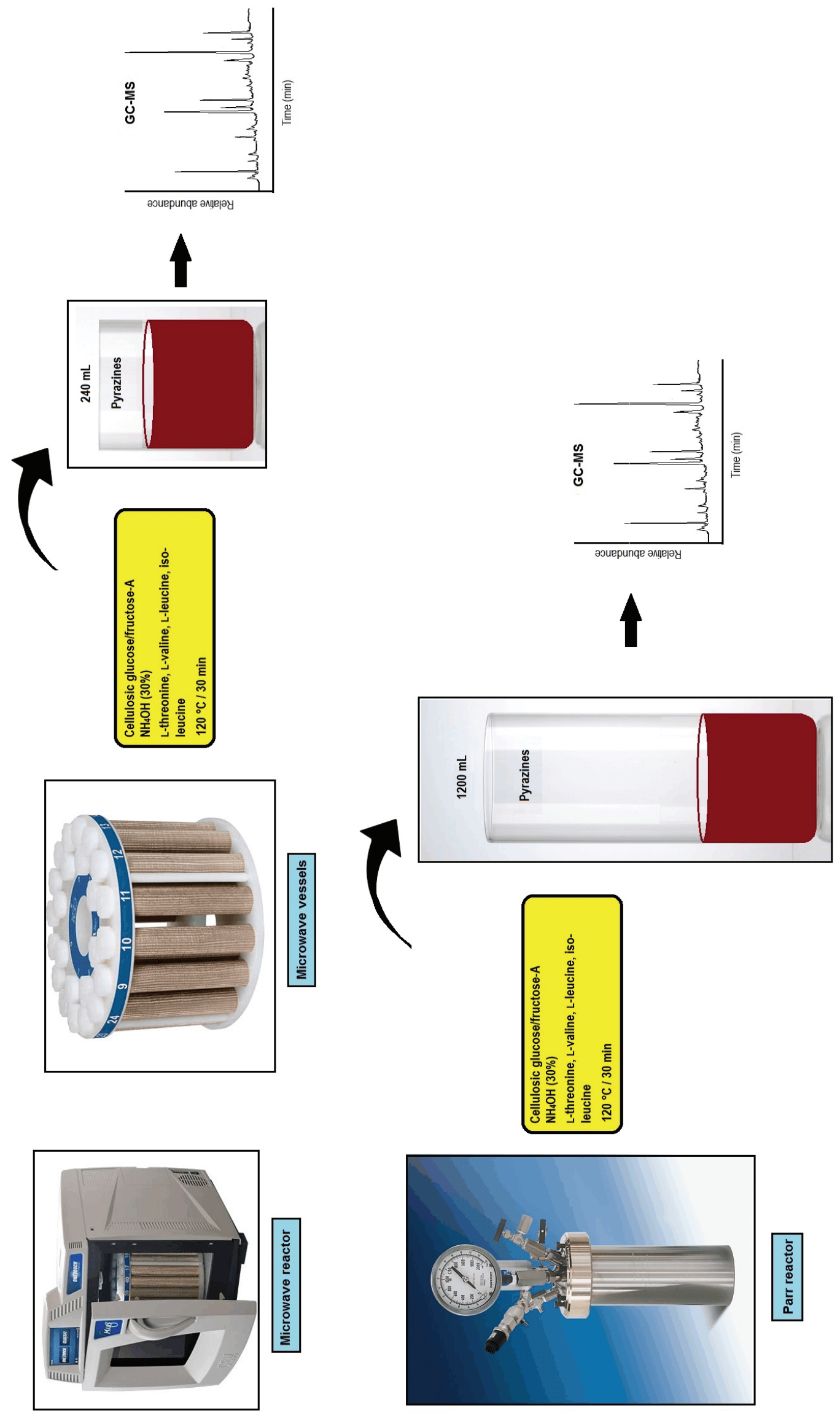

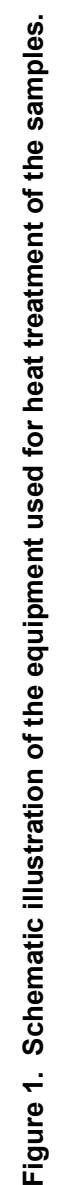


mass spectra with those in the Wiley mass spectral library. Heat treatment of the samples were conducted employing the Mars Xpress microwave model MES-1000 (CEM Corporation, Matthews, NC, USA), with $800 \mathrm{~W}$ microwave power and $2450 \mathrm{MHz}$ microwave frequency and a Parr Reactor model 4842 (Parr Instrument Company, Moline, IL, USA) (Figure 1).

\section{RESULTS AND DISCUSSION}

\section{Pyrazine synthesis using microwave reactor}

Preliminary experiments were performed to determine the best conditions for pyrazine synthesis with a microwave reactor. In all experiments, cellulosic glucose/fructose (CGFA) as a sugar source (41 g), different amino acids (Lthreonine, L-valine, L-isoleucine, and L-leucine), and variable volumes of $30 \% \mathrm{NH}_{4} \mathrm{OH}$ as the nitrogen source were used for synthesis. In addition to water soluble pyrazines, many of these early syntheses revealed an intractable dark brown, tarry "sludge" which had not been reported previously with either open vessels or sealed vessels. Early in the investigation, it was surmised that the origin of the "sludge" might be due to either relatively high amino acid concentrations or inefficient heating that either caused incomplete reactions or produced byproducts at high temperatures. It is very important to note here that not every synthesis via microwave heating resulted in "sludge" formation. Those conditions wherein "sludge" was produced with microwave radiation contained a large amount of amino acids. In spite of this issue, our preliminary synthetic study revealed certain conditions where no "sludge" was observed.
In this regard, the effect of experimental variables such as $\mathrm{NH}_{4} \mathrm{OH}$ concentration, amino acid concentration, reaction time and temperature, and aqueous reaction volume on the amounts of high quality pyrazines were optimized with the mass of cellulosic glucose/fructose fixed. Since one of the main goals of our study was to scale up the final mixture of products, reactions were initially done using a small scale industrial microwave with a vessel volume of $30 \mathrm{~mL}$. For larger scale reactions, eight separate Teflon vessels each with a volume of $30 \mathrm{~mL}$ were employed. After completion of each larger-scale synthesis, the contents of all eight vessels were mixed. The combined $240 \mathrm{~mL}$ solution was then divided into $30 \mathrm{~mL}$ aliquots for extraction with $10 \mathrm{~mL}$ of methylene chloride after addition of a 25 ppm internal standard. Finally, triplicate injections of $1 \mu \mathrm{L}$ of extract to the GC column were made.

\section{Effect of $\mathrm{NH}_{4} \mathrm{OH}$ concentration}

In the first part of the study, $41 \mathrm{~g}$ of CGF-A, $0.96 \mathrm{~g}$ of Lthreonine (T), $0.56 \mathrm{~g}$ of L-valine (V), $0.5 \mathrm{~g}$ of L-leucine (L), and $0.5 \mathrm{~g}$ of L-isoleucine (iso-L) with different volumes of $30 \% \mathrm{NH}_{4} \mathrm{OH}$ were reacted at $110{ }^{\circ} \mathrm{C}$ for $30 \mathrm{~min}$ with a ramp of $1.7^{\circ} \mathrm{C} / \mathrm{min}$. Water was added to each vessel to adjust the combined reaction volumes of the eight microwave vessels to $240 \mathrm{~mL}$. After the reaction the mixture was allowed to cool, the extraction was performed on $30 \mathrm{~mL}$ aliquots of the total volume with $10 \mathrm{~mL}$ of $\mathrm{CH}_{2} \mathrm{Cl}_{2}$ per extraction. Table 1 shows the individual, identified pyrazine components and their mass per synthesis resulting from two different concentrations of $\mathrm{NH}_{4} \mathrm{OH}$.

Table 1. Identified pyrazine components and their mass per synthesis resulting from two different concentrations of $\mathrm{NH}_{4} \mathrm{OH}$ (in $\mu \mathrm{g}$ ): CGF-A (41 g), amino acids: $0.96(\mathrm{~T}) / 0.56(\mathrm{~V}) / 0.5(\mathrm{~L}) / 0.5$ (iso-L) g; hold: $30 \mathrm{~min}$, ramp: $1.7^{\circ} \mathrm{C} / \mathrm{min}$, final temperature: $110^{\circ} \mathrm{C}$, power: 800 watts, total reaction volume: $240 \mathrm{~mL}$, extraction conditions: $30 \mathrm{~mL}$ aliquot per $10 \mathrm{~mL}$ DCM.

\begin{tabular}{|c|c|c|c|c|c|c|}
\hline $\mathrm{R}_{\mathrm{t}}(\min )$ & Identified compound & C\# & $\mathrm{NH}_{4} \mathrm{OH}(18.5 \mathrm{~mL})$ & $\%$ of total & $\mathrm{NH}_{4} \mathrm{OH}(28.0 \mathrm{~mL})$ & $\%$ of total \\
\hline 6.2 & Pyrazine & & 2795 & 7.0 & 2924 & 4.0 \\
\hline 6.8 & 2-Methylpyrazine & C1 & 18,146 & 48.0 & 24,159 & 51.0 \\
\hline 7.5 & 2,5-Dimethylpyrazine & $\mathrm{C} 2$ & 1827 & 5.0 & 2096 & 5.0 \\
\hline 7.6 & 2,6-Dimethylpyrazine & $\mathrm{C} 2$ & 11,134 & 29.0 & 12,604 & 27.0 \\
\hline 7.8 & 2,3-Dimethylpyrazine & $\mathrm{C} 2$ & 1384 & 4.0 & 1476 & 3.0 \\
\hline 8.1 & 2-Ethyl-6methylpyrazine & C3 & 441 & 1.0 & 511 & 1.1 \\
\hline 8.2 & 2-Ethyl-5methylpyrazine & C3 & 84 & 0.2 & 68 & 0.1 \\
\hline 8.4 & 2,3,5-Trimethylpyrazine & C3 & 1192 & 3.0 & 1534 & 3.0 \\
\hline 8.6 & 2-Vinylpyrazine & $\mathrm{C} 2$ & 46 & 0.1 & 57 & 0.1 \\
\hline 8.7 & 3-Ethyl-2,5-dimethylpyrazine & $\mathrm{C} 4$ & 75 & 0.2 & 103 & 0.2 \\
\hline 8.8 & 2-Methylpropylpyrazine & $\mathrm{C} 4$ & ND & ND & ND & ND \\
\hline 8.86 & 2,6-Dimethylpyrazine & $\mathrm{C} 4$ & ND & ND & 104 & 0.2 \\
\hline 8.9 & 2,6-Dimethyl-3-ethylpyrazine & $\mathrm{C} 4$ & ND & ND & ND & ND \\
\hline 9 & 2,3,5,6-Tetramethylpyrazine & $\mathrm{C} 4$ & 37 & 0.1 & 58 & 0.1 \\
\hline 9.1 & 2-Butyl-3-methylpyrazine & C5 & 94 & 0.2 & ND & ND \\
\hline 9.2 & 2-Methyl-3-(2-methylpropyl)pyrazine & C5 & 83 & 0.2 & 80 & 0.2 \\
\hline 9.3 & 2,3,5-Trimethyl-6-ethylpyrazine & C5 & 42 & 0.1 & 54 & 0.1 \\
\hline 9.4 & 2,5-Dimethyl-3-isobutylpyrazine & $\mathrm{C} 6$ & 53 & 0.1 & 55 & 0.1 \\
\hline 9.8 & 2-Pentylpyrazine & C5 & 95 & 0.2 & 227 & 0.5 \\
\hline 10 & 3-Methylbutylpyrazine & C5 & 330 & 1.0 & 788 & 2.0 \\
\hline 10.3 & 2-Isopentyl-6-methylpyrazine & C6 & 193 & 0.4 & 663 & 1.0 \\
\hline- & Pyrazines per extraction $(\mu \mathrm{g})$ & - & 38,051 & - & 47,563 & - \\
\hline- & Pyrazines per total reaction $(\mathrm{g})$ & - & 0.30 & - & 0.38 & - \\
\hline- & CGF-A to total syn pyrazines mass ratio & - & 137 & - & 108 & - \\
\hline
\end{tabular}


As can be observed $C_{1}-C_{3}$ pyrazines were eluted 7-8.5 min and branched $\mathrm{C}_{4}-\mathrm{C}_{6}$ pyrazines were eluted 8.7-10.5 min. Since pyrazine and 2-methylpyrazine are the less desirable pyrazines from an odor threshold and sensory characteristic perspective, their combined contribution to the total pyrazines is noted here for comparison. Regardless of the volume of ammonium hydroxide used, the percentage of pyrazine (pyz) plus 2-methylpyrazine (2-met) was 55\% of the total. In other words, over half of the synthesized watersoluble pyrazines was not desirable for the intended purpose of the synthesis.

On the other hand, seventeen different alkylpyrazines were detected and quantified. Only one, 2-isopentyl-6-methylpyrazine, was highly branched. A small amount of unsubstituted pyrazine was found in both syntheses. Various methylpyrazines (i.e., 2-methylpyrazine and 2,6-dimethylpyrazine) made up over $60 \%$ of all isolated alkylpyrazines. The total amounts of isolated alkylpyrazines using $18.5 \mathrm{~mL}$ of $\mathrm{NH}_{4} \mathrm{OH}$ was approximately $38,000 \mu \mathrm{g}$; while the total amount of isolated alkylpyrazines obtained using $28 \mathrm{~mL}$ of $\mathrm{NH}_{4} \mathrm{OH}$ was approximately 48,000 $\mu \mathrm{g}$. Accordingly, $28 \mathrm{~mL}$ of $\mathrm{NH}_{4} \mathrm{OH}$ was selected for the remainder of the experiments.

\section{Effect of temperature and time}

The effect of temperature and time on the yield of pyrazines were next investigated. The same conditions that were used in the previous experiments using $28 \mathrm{~mL}$ of $30 \% \mathrm{NH}_{4} \mathrm{OH}$ were performed at 110,120 , and $130{ }^{\circ} \mathrm{C}$ for $30 \mathrm{~min}$. As before, water was added to adjust the combined reaction volumes of the eight microwave vessels to $240 \mathrm{~mL}$. Table 2 shows the individual, identified pyrazine components and their total mass per synthesis resulting from the different test temperatures. The lowest temperature tested $\left(110^{\circ} \mathrm{C}\right)$ gave the lowest amount of total pyrazines and a relatively high (pyz+2-met) percentage of 53\%. The two higher temperatures yielded approximately the same total masses but a higher percentage (pyz+2-met) of $48 \%$ and $47 \%$. Nearly $80 \%$ of the total yield at each of the three temperatures was 2-methylpyrazine, 2,5-dimethylpyrazine, 2,6-dimethylpyrazine, and 2,3-dimethylpyrazine. The remaining fifteen pyrazines were each less than $1 \%$ of the total except for 2,3,5-trimethylpyrazine which was 4-5\% of the total. For $130{ }^{\circ} \mathrm{C}$, a thin layer of "sludge" was formed at the bottom of the microwave vessel. Accordingly, for the rest of our experiments, $120^{\circ} \mathrm{C}$ was chosen as the optimum reaction temperature, where no "sludge" was produced and the yield was higher.

Table 3 shows the individual identified pyrazine components and their mass per combined ( 8 vessels) syntheses resulting from different reaction times (30 and $60 \mathrm{~min}$ ). In this case the lower time yielded the greater overall yield of pyrazines with the methylpyrazines noted above again accounting for over $85 \%$ of the 18 total pyrazines detected and quantified.

\section{Effect of amino acid type}

Table 4 shows the yield of synthesized alkylpyrazines via microwave with different amino acids incorporated into the reaction keeping the sugar source and ammonium hydroxide concentration as noted in the Table. The mass of individual amino acids (L-threonine, L-valine, L-leucine, and L-isoleucine) were maintained at their highest possible concentrations without "sludge" formation.

Table 2. Identified pyrazine components and their total mass per synthesis resulting from the different test temperatures (in $\mu \mathrm{g}$ ): $\mathrm{NH}_{4} \mathrm{OH}(28 \mathrm{~mL})$, CGF-A $(41 \mathrm{~g})$, amino acids: $0.96(\mathrm{~T}) / 0.56(\mathrm{~V}) / 0.5(\mathrm{~L}) / 0.5$ (iso-L) g, hold: $30 \mathrm{~min}$, ramp: $1.7^{\circ} \mathrm{C} / \mathrm{min}$, final temperature: $110^{\circ} \mathrm{C}, 120^{\circ} \mathrm{C}$, and $130{ }^{\circ} \mathrm{C}$, power: 800 watts, total reaction volume: $240 \mathrm{~mL}$, extraction conditions: $30 \mathrm{~mL}$ aliquot per $10 \mathrm{~mL} \mathrm{DCM}$.

\begin{tabular}{|c|c|c|c|c|c|c|c|c|}
\hline $\mathrm{R}_{\mathrm{t}}(\min )$ & Identified compound & $\mathrm{C \#}$ & $110^{\circ} \mathrm{C}$ & $\%$ of total & $120^{\circ} \mathrm{C}$ & $\%$ of total & $130^{\circ} \mathrm{C}$ & $\%$ of total \\
\hline 6.2 & Pyrazine & & 1910 & 6.0 & 2565 & 6.0 & 2581 & 6.0 \\
\hline 6.8 & 2-Methylpyrazine & $\mathrm{C} 1$ & 15,863 & 47.0 & 17,628 & 42.0 & 17,071 & 41.0 \\
\hline 7.5 & 2,5-Dimethylpyrazine & $\mathrm{C} 2$ & 2619 & 8.0 & 3950 & 9.5 & 3989 & 10.0 \\
\hline 7.6 & 2,6-Dimethylpyrazine & $\mathrm{C} 2$ & 9571 & 28.5 & 11,942 & 29.0 & 12,024 & 29.0 \\
\hline 7.8 & 2,3-Dimethylpyrazine & $\mathrm{C} 2$ & 1056 & 3.0 & 1608 & 4.0 & 1581 & 4.0 \\
\hline 8.1 & 2-Ethyl-6 methylpyrazine & C3 & 289 & 1.0 & 549 & 1.3 & 686 & 2.0 \\
\hline 8.2 & 2-Ethyl-5 methylpyrazine & $\mathrm{C} 3$ & 69 & 0.2 & 119 & 0.3 & 130 & 0.3 \\
\hline 8.4 & 2,3,5-Trimethylpyrazine & $\mathrm{C} 3$ & 1268 & 4.0 & 2095 & 5.0 & 2263 & 5.5 \\
\hline 8.6 & 2-Vinylpyrazine & $\mathrm{C} 2$ & 78 & 0.2 & 97 & 0.2 & 63 & 0.2 \\
\hline 8.7 & 2,5-Dimethyl-3-ethylpyrazine & $\mathrm{C} 4$ & 57 & 0.2 & 108 & 0.3 & 131 & 0.3 \\
\hline 8.9 & 2,6-Dimethylpyrazine & $\mathrm{C} 4$ & 72 & 0.2 & 136 & 0.3 & 174 & 0.4 \\
\hline 9 & 2,3,5,6-Tetramethylpyrazine & $\mathrm{C} 4$ & 59 & 0.2 & 113 & 0.3 & 134 & 0.3 \\
\hline 9.3 & 2,3,5-Trimethyl-6-ethylpyrazine & $\mathrm{C} 5$ & 14 & 0.0 & 32 & 0.1 & 41 & 0.1 \\
\hline 9.4 & 2,5-Dimethyl-3-isobutylpyrazine & $\mathrm{C} 6$ & 38 & 0.1 & 64 & 0.2 & 61 & 0.1 \\
\hline 9.8 & 2-Pentylpyrazine & C5 & 58 & 0.2 & 83 & 0.2 & 69 & 0.2 \\
\hline 9.9 & 3-Methylbutylpyrazine & C5 & 251 & 0.7 & 360 & 1.0 & 285 & 0.7 \\
\hline 10.3 & 2-Isopentyl-6-methylpyrazine & $\mathrm{C} 6$ & 167 & 0.5 & 261 & 0.6 & 244 & 0.6 \\
\hline 10.6 & 2,6-Dimethyl-3-butylpyrazine & $\mathrm{C} 7$ & 107 & 0.3 & 147 & 0.4 & 130 & 0.3 \\
\hline- & Pyrazines per extraction $(\mu \mathrm{g})$ & - & 33,546 & - & 41,860 & - & 41,658 & - \\
\hline- & Pyrazines per total reaction $(\mathrm{g})$ & - & 0.27 & - & 0.34 & - & 0.33 & - \\
\hline- & CGF-A to total syn pyrazines mass ratio & - & 152 & - & 121 & - & 124 & - \\
\hline
\end{tabular}


Table 3. Identified pyrazine components and their mass per combined ( 8 vessels) syntheses resulting from different reaction times (30 and $60 \mathrm{~min}$ ) (in $\mu \mathrm{g}$ ):

$\mathrm{NH}_{4} \mathrm{OH}(28 \mathrm{~mL}), \mathrm{CGF}-\mathrm{A}(41 \mathrm{~g})$, amino acids: $0.96(\mathrm{~T}) / 0.56(\mathrm{~V}) / 0.5(\mathrm{~L}) / 0.5$ (iso-L) g; ramp: $1.7^{\circ} \mathrm{C} / \mathrm{min}$, final temperature: $120{ }^{\circ} \mathrm{C}$, time: $30 \mathrm{~min}$ and $60 \mathrm{~min}$, power: 800 watts, total reaction volume: $240 \mathrm{~mL}$, extraction conditions: $30 \mathrm{~mL}$ aliquot per $10 \mathrm{~mL}$ DCM.

\begin{tabular}{|c|c|c|c|c|c|c|}
\hline $\mathrm{R}_{\mathrm{t}}(\min )$ & Identified compound & $\mathrm{C \#}$ & $30 \mathrm{~min}$ & $\%$ of total & $60 \min$ & $\%$ of total \\
\hline 6.2 & Pyrazine & & 2565 & 6.0 & 2347 & 6.0 \\
\hline 6.8 & 2-Methylpyrazine & C1 & 17,628 & 42.0 & 16,068 & 42.0 \\
\hline 7.5 & 2,5-Dimethylpyrazine & $\mathrm{C} 2$ & 3950 & 9.0 & 3566 & 9.0 \\
\hline 7.6 & 2,6-Dimethylpyrazine & $\mathrm{C} 2$ & 11,942 & 29.0 & 11,249 & 29.0 \\
\hline 7.8 & 2,3-Dimethylpyrazine & $\mathrm{C} 2$ & 1608 & 4.0 & 1426 & 4.0 \\
\hline 8.1 & 2-Ethyl-6 methylpyrazine & C3 & 549 & 1.5 & 582 & 1.5 \\
\hline 8.2 & 2-Ethyl-5 methylpyrazine & C3 & 119 & 0.3 & 113 & 0.3 \\
\hline 8.4 & 2,3,5-Trimethylpyrazine & C3 & 2095 & 5.0 & 1967 & 5.0 \\
\hline 8.6 & 2-Vinylpyrazine & $\mathrm{C} 2$ & 97 & 0.2 & 57 & 0.1 \\
\hline 8.7 & 2,5-Dimethyl-3-ethylpyrazine & $\mathrm{C} 4$ & 108 & 0.3 & 107 & 0.3 \\
\hline 8.9 & 2,6-Dimethylpyrazine & C4 & 136 & 0.3 & 145 & 0.4 \\
\hline 9 & 2,3,5,6-Tetramethylpyrazine & $\mathrm{C} 4$ & 113 & 0.3 & 117 & 0.3 \\
\hline 9.3 & 2,3,5-Trimethyl-6-ethylpyrazine & C5 & 32 & 0.1 & 36 & 0.1 \\
\hline 9.4 & 2,5-Dimethyl-3-isobutylpyrazine & C6 & 64 & 0.2 & 58 & 0.1 \\
\hline 9.8 & 2-Pentylpyrazine & C5 & 83 & 0.2 & 69 & 0.2 \\
\hline 9.9 & 3-Methylbutylpyrazine & C5 & 360 & 0.9 & 314 & 0.8 \\
\hline 10.3 & 2-Isopentyl-6-methylpyrazine & C6 & 261 & 0.6 & 268 & 0.7 \\
\hline 10.6 & 2,6-Dimethyl-3-butylpyrazine & $\mathrm{C} 7$ & 147 & 0.4 & 133 & 0.3 \\
\hline- & Pyrazines per extraction $(\mu \mathrm{g})$ & - & 41,860 & - & 38,621 & - \\
\hline - & Pyrazines per total reaction $(\mathrm{g})$ & - & 0.34 & - & 0.30 & - \\
\hline - & CGF-A to total syn pyrazines mass ratio & - & 121 & - & 137 & - \\
\hline
\end{tabular}

Table 4. Yield of synthesized alkylpyrazines via microwave with different amino acids (in $\mu \mathrm{g}$ ):

$\mathrm{NH}_{4} \mathrm{OH}(28 \mathrm{~mL}), \mathrm{CGF}-\mathrm{A}(41 \mathrm{~g})$, hold: $30 \mathrm{~min}$, ramp: $1.7^{\circ} \mathrm{C} / \mathrm{min}, 120^{\circ} \mathrm{C}, 800$ watts, total reaction volume: $240 \mathrm{~mL}$, extraction conditions: $30 \mathrm{~mL}$ aliquot per $10 \mathrm{~mL}$ DCM.

\begin{tabular}{|c|c|c|c|c|c|c|c|c|c|c|}
\hline $\begin{array}{l}\mathrm{R}_{\mathrm{t}} \\
(\min )\end{array}$ & Identified compound & C\# & $\begin{array}{c}\mathrm{T} \\
(0.96 \mathrm{~g})\end{array}$ & $\%$ total & $\begin{array}{c}V \\
(0.56 \mathrm{~g})\end{array}$ & $\%$ total & $\begin{array}{c}\mathrm{L} \\
(0.5 \mathrm{~g})\end{array}$ & $\%$ total & $\begin{array}{l}\text { iso-L } \\
(0.5 \mathrm{~g})\end{array}$ & $\%$ total \\
\hline 6.2 & Pyrazine & & 1137 & 9.0 & 1011 & 8.5 & 3319 & 24.0 & 965 & 8.0 \\
\hline 6.8 & 2-Methylpyrazine & $\mathrm{C} 1$ & 5900 & 46.0 & 5687 & 48.0 & 5708 & 41.0 & 6287 & 54.0 \\
\hline 7.5 & 2,5-Dimethylpyrazine & $\mathrm{C} 2$ & 1155 & 9.0 & 1131 & 9.5 & 1047 & 7.5 & 934 & 8.0 \\
\hline 7.6 & 2,6-Dimethylpyrazine & $\mathrm{C} 2$ & 3321 & 26.0 & 3032 & 25.0 & 2926 & 21.0 & 2570 & 22.0 \\
\hline 8.1 & 2,3-Dimethylpyrazine & $\mathrm{C} 2$ & 450 & 4.0 & 408 & 3.0 & 388 & 3.0 & 359 & 3.0 \\
\hline 8.2 & 2-Ethyl-6 methylpyrazine & $\mathrm{C} 3$ & 121 & 1.0 & 63 & 0.5 & 62 & 0.4 & 43 & 0.4 \\
\hline 8.4 & 2-Ethyl-5 methylpyrazine & $\mathrm{C} 3$ & 38 & 0.3 & 21 & 0.2 & 20 & 0.1 & 15 & 0.1 \\
\hline 8.5 & 2,3,5-Trimethylpyrazine & C3 & 500 & 4.0 & 440 & 4.0 & 390 & 3.0 & 341 & 3.0 \\
\hline 8.6 & 2-Vinylpyrazine & $\mathrm{C} 2$ & 48 & 0.4 & 44 & 0.4 & 47 & 0.3 & 44 & 0.4 \\
\hline 8.7 & 3-Ethyl-2,5-dimethylpyrazine & $\mathrm{C} 4$ & 21 & 0.2 & 6 & 0.1 & 9 & 0.1 & 0 & ND \\
\hline 8.8 & 2,6-Dimethyl-3-ethylpyrazine & $\mathrm{C} 4$ & 37 & 0.3 & 14 & 0.1 & 13 & 0.1 & ND & ND \\
\hline 8.9 & 2,6-Diethylpyrazine & $\mathrm{C} 4$ & 27 & 0.2 & ND & ND & ND & ND & 10 & 0.1 \\
\hline 9 & 2,3,5,6-Tetramethylpyrazine & $\mathrm{C} 4$ & 21 & 0.2 & 19 & 0.2 & 16 & 0.1 & 14 & 0.1 \\
\hline 9.2 & 2-Butyl-3-methylpyrazine & C5 & 14 & 0.1 & ND & ND & ND & ND & ND & ND \\
\hline 9.5 & 2,3,5-Trimethyl-6-ethylpyrazine & C5 & 7 & 0.1 & ND & ND & ND & ND & ND & ND \\
\hline 9.8 & $\begin{array}{l}\text { 2-(2-Methylpropyl)-3,6- } \\
\text { dimethylpyrazine }\end{array}$ & C6 & ND & ND & 18 & 0.2 & ND & ND & ND & ND \\
\hline 10.1 & 2,5-Dimethyl-3-isobutylpyrazine & C6 & ND & ND & 23 & 0.2 & ND & ND & ND & ND \\
\hline 10 & 3-Methylbutylpyrazine & C5 & ND & ND & ND & ND & ND & ND & 14 & 0.1 \\
\hline 10.3 & 2-Isopentyl-6-methylpyrazine & C6 & 11 & 0.1 & ND & ND & 61 & 0.4 & ND & ND \\
\hline 10.6 & 2,6-Dimethyl-3-butylpyrazine & $\mathrm{C} 7$ & ND & ND & ND & ND & ND & ND & 160 & 0.5 \\
\hline- & Pyrazines per extraction $(\mu \mathrm{g})$ & - & 12,800 & - & 11,919 & - & 14,004 & - & 11,754 & - \\
\hline- & Pyrazines per total reaction $(\mathrm{g})$ & - & 0.1 & - & 0.09 & - & 0.1 & - & 0.09 & - \\
\hline- & $\begin{array}{l}\text { CGF-A to total syn pyrazines } \\
\text { mass ratio }\end{array}$ & - & 410 & - & 456 & - & 410 & - & 456 & - \\
\hline
\end{tabular}


L-Leucine and L-threonine gave the highest mass of total pyrazines although the difference among the four amino acids was hardly significant. For this experiment, the percentage of the total for pyrazine (pyz) plus 2-methylpyrazine (2-met) was $55 \%$ for threonine, $56.5 \%$ for valine, $65 \%$ for leucine, and $62 \%$ for L-isoleucine.

Additional observations can be made here. 1) The mass of unsubstituted pyrazine was double to that with L-leucine relative to the other three amino acids; 2) Less branching with L-leucine was realized; 3) 2,3,5-Trimethylpyrazine accounted for $5 \%$ of the total isolated pyrazines regardless of the amino acid; 4) 2,6-Dimethylpyrazine (C4) was made by using L-threonine and L-isoleucine; 5) Low amounts of 2-butyl-3-methylpyrazine and 2,3,5-trimethyl-6-ethylpyrazine (C5) were produced by using L-threonine; 6) 2-Pentylpyrazine was mainly synthesized using L-leucine; while, a small amount was made with L-threonine; 7) The main source of 2-(2-methylpropyl)-3,6-dimethylpyrazine and 2,5-dimethyl-3-isobutylpyrazine (C6) was L-valine; 8) Five $+/-2$ of the 18 pyrazines monitored were not detected when amino acids were incorporated into the synthesis.

\section{Pyrazine synthesis using Parr reactor}

The second part of the study employed a 1.5-L stainless steel Parr vessel for pyrazine synthesis using cellulosic glucose/fructose-A (CGF-A) as the sugar source. In this way, the experiments could be performed in a single vessel with a total reaction volume of $240 \mathrm{~mL}$. This allowed us to simulate the same overall conditions for both microwave and Parr techniques (i.e., one vessel $240 \mathrm{~mL}$ versus eight combined vessels of $30 \mathrm{~mL}$ each). Initially, the same reaction conditions with Parr that were applied for microwave, (i.e., $41 \mathrm{~g}$ CGF-A, $0.96 \mathrm{~g}$ L-threonine (T), $0.56 \mathrm{~g} \mathrm{L-}$ valine (V), $0.5 \mathrm{~g}$ L-leucine (L) and $0.5 \mathrm{~g} \mathrm{~L}$-isoleucine (isoL) and $28 \mathrm{~mL}$ of $30 \% \mathrm{NH}_{4} \mathrm{OH}$ at $120{ }^{\circ} \mathrm{C}$ for $30 \mathrm{~min}$ with a ramp of $1.7^{\circ} \mathrm{C} / \mathrm{min}$ ) were employed. Surprisingly, a lot of "sludge" was observed at the bottom of the Parr vessel (Figure 2).

Investigation of the effect of reaction volume on production of the "sludge" was studied next. Syntheses were done in variable reaction volumes of $480 \mathrm{~mL}, 1000 \mathrm{~mL}$, and $1200 \mathrm{~mL}$. For the $480-\mathrm{mL}$ and $1000-\mathrm{mL}$ reaction volumes, different amounts of "sludge" were observed. Whereas, with a reaction volume of $1200 \mathrm{~mL}$, no "sludge" was produced. An interesting comparison here is that "sludge" was produced with a reaction volume of $240 \mathrm{~mL}$ using the Parr reactor; while no "sludge" was observed by means of microwave energy using the same synthesis parameters in the 240-mL reaction volume. An explanation for this observation will come later. Thus, for the remainder of the Parr reactor studies, a reaction volume of $1200 \mathrm{~mL}$ was chosen.

\section{Effect of temperature}

The effect of temperature on the yield and selectivity of pyrazines with the Parr reactor was first investigated. Reaction conditions were $41 \mathrm{~g}$ of CGF-A, $0.96 \mathrm{~g}$ L-threonine (T), $0.56 \mathrm{~g}$ L-valine (V), $0.5 \mathrm{~g}$ L-leucine (L), $0.5 \mathrm{~g}$ of L-isoleucine (iso-L), and $28 \mathrm{~mL}$ of $30 \% \mathrm{NH}_{4} \mathrm{OH}$ at 110 , 120 , and $130{ }^{\circ} \mathrm{C}$ for $30 \mathrm{~min}$ with a ramp of $1.7{ }^{\circ} \mathrm{C} / \mathrm{min}$. Water was added to adjust the reaction volume to $1200 \mathrm{~mL}$.

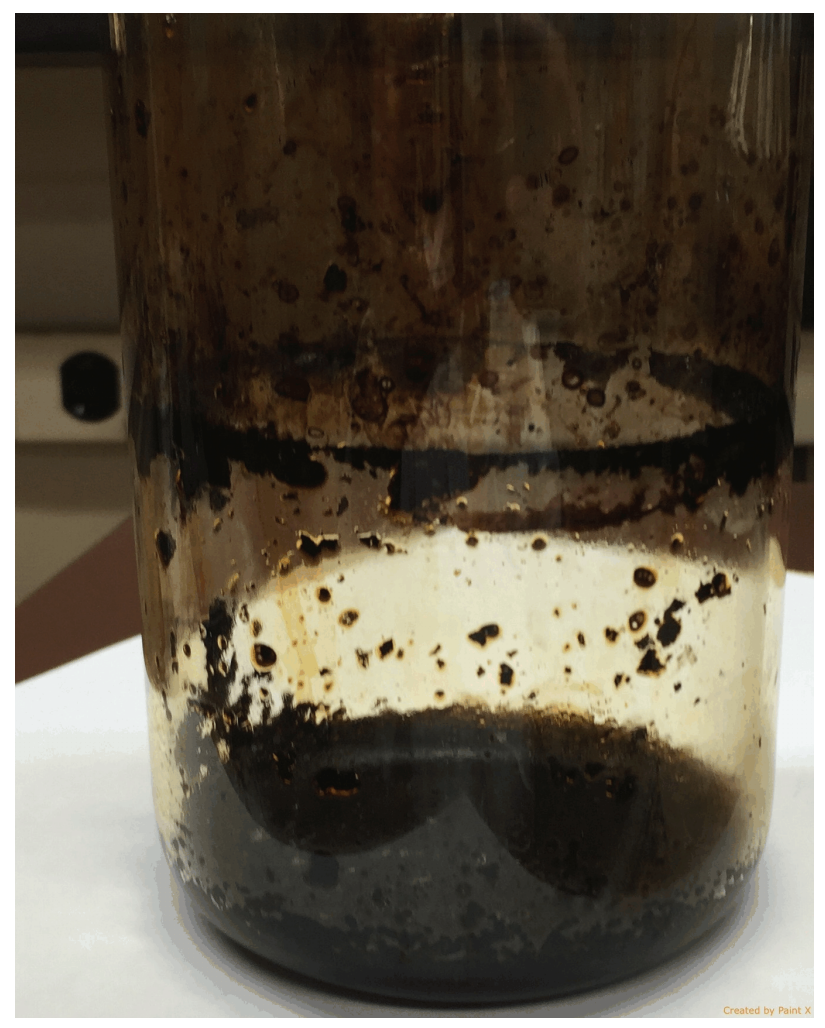

Figure 2. Photo of intractable byproduct ("sludge") of various pyrazine syntheses employing either a microwave or Parr reactor and variable but specific reactant concentrations.

After the reaction was allowed to cool, extraction was done on $30 \mathrm{~mL}$ aliquots of the entire reaction with successive $10 \mathrm{~mL}$ of $\mathrm{CH}_{2} \mathrm{Cl}_{2}$. Table 5 shows the individual identified alkylpyrazines and their mass per total synthesis resulting from the different reaction temperatures. Yields of synthesized pyrazines at $120^{\circ} \mathrm{C}$ and $130^{\circ} \mathrm{C}$ were similar; whereas yield for $110^{\circ} \mathrm{C}$ was slightly lower. Percentages of pyz +2 met with the Parr reactor were higher $(69.0,65.7$, and $61.6 \%$ ) in general than via microwave conditions.

Selectivity for methylpyrazines was slightly higher, as the combined percentage of the total for 2-methylpyrazine, 2,5-dimethylpyrazine, 2,6-dimethylpyrazine, and 2,3-dimethylpyrazine was approximately $87 \%$. The other individual alkylpyrazines were all less than $0.3 \%$ of the total with the exception of 2,3,5-trimethylpyrazine which ranged from $3 \%$ to $4 \%$ at the three temperatures studied. Accordingly, for the remainder of the Parr experiments, $120{ }^{\circ} \mathrm{C}$ was chosen as the optimum reaction temperature.

\section{Effect of time}

For investigation of the effect of time on the yield of alkylpyrazines with the Parr reactor, the same reaction conditions described previously were applied. Table 6 shows the individual identified pyrazine components and their mass-per-synthesis resulting from different times of reaction. The results of two experiments were similar. $\mathrm{C} 1 / \mathrm{C} 2$ methylpyrazines when combined made up over $83 \%$ of the total while 2,3,5-trimethylpyrazine was again approximately $4 \%$ of the total which compared well with the previous temperature study. This finding gave very encouraging results. 
Table 5. Identified alkylpyrazines and their mass per total synthesis resulting from the different reaction temperatures (in $\mu \mathrm{g}$ ): $\mathrm{NH}_{4} \mathrm{OH}\left(28 \mathrm{~mL}\right.$ ), CGF-A (41 g), $0.96(\mathrm{~T}) / 0.56(\mathrm{~V}) / 0.5(\mathrm{~L}) / 0.5$ (iso-L) g; $30 \mathrm{~min}$, ramp: $1.7^{\circ} \mathrm{C} / \mathrm{min}$, temperature: 110,120 , and $130{ }^{\circ} \mathrm{C}$, total reaction volume: $1200 \mathrm{~mL}$, extraction conditions: $30 \mathrm{~mL}$ aliquot per $10 \mathrm{~mL} \mathrm{DCM}$.

\begin{tabular}{|c|c|c|c|c|c|c|c|c|}
\hline $\mathrm{R}_{\mathrm{t}}(\min )$ & Identified compound & $\mathrm{C \#}$ & $110^{\circ} \mathrm{C}$ & $\%$ total & $120^{\circ} \mathrm{C}$ & $\%$ total & $130^{\circ} \mathrm{C}$ & $\%$ total \\
\hline 6.2 & Pyrazine & - & 707 & 6.1 & 1028 & 6.7 & 908 & 6.0 \\
\hline 6.8 & 2-Methylpyrazine & C1 & 7266 & 62.6 & 9122 & 59.0 & 8470 & 55.6 \\
\hline 7.5 & 2,5-Dimethylpyrazine & $\mathrm{C} 2$ & 715 & 6.2 & 987 & 6.4 & 1062 & 7.0 \\
\hline 7.6 & 2,6-Dimethylpyrazine & $\mathrm{C} 2$ & 2027 & 17.5 & 2876 & 18.6 & 2969 & 19.5 \\
\hline 7.8 & 2,3-Dimethylpyrazine & $\mathrm{C} 2$ & 288 & 2.5 & 419 & 2.7 & 453 & 3.0 \\
\hline 8.1 & 2-Ethyl-6 methylpyrazine & C3 & 71 & 0.6 & 123 & 0.8 & 174 & 1.1 \\
\hline 8.2 & 2-Ethyl-5 methylpyrazine & $\mathrm{C} 3$ & 23 & 0.2 & 37 & 0.2 & 51 & 0.3 \\
\hline 8.4 & 2,3,5-Trimethylpyrazine & $\mathrm{C} 3$ & 342 & 2.9 & 516 & 3.3 & 630 & 4.1 \\
\hline 8.6 & 2-Vinylpyrazine & $\mathrm{C} 2$ & 19 & 0.2 & 22 & 0.1 & 18 & 0.1 \\
\hline 8.7 & 3-Ethyl-2,5-dimethylpyrazine & $\mathrm{C} 4$ & ND & ND & 37 & 0.2 & 83 & 0.5 \\
\hline 8.8 & 2-Methylpropylpyrazine & $\mathrm{C} 4$ & 16 & 0.1 & 47 & 0.3 & ND & ND \\
\hline 8.9 & 2,6-Diethylpyrazine & $\mathrm{C} 4$ & 25 & 0.2 & ND & ND & 75 & 0.5 \\
\hline 9 & 2,3,5,6-Tetramethylpyrazine & $\mathrm{C} 4$ & 21 & 0.2 & 37 & 0.2 & 50 & 0.3 \\
\hline 9.2 & 2-Methyl-3-(2-methylpropyl)pyrazine & C5 & 14 & 0.1 & 19 & 0.1 & 24 & 0.2 \\
\hline 9.3 & 2,3,5-Trimethyl-6-ethylpyrazine & C5 & ND & ND & 13 & 0.1 & 26 & 0.2 \\
\hline 9.4 & 2,5-Dimethyl-3-isobutylpyrazine & C6 & ND & ND & 14 & 0.1 & 29 & 0.2 \\
\hline 9.8 & 2-Pentylpyrazine & $\mathrm{C} 5$ & ND & ND & 14 & 0.1 & 14 & 0.1 \\
\hline 9.9 & 3-Methylbutyl pyrazine & C5 & 32 & 0.3 & 47 & 0.3 & 64 & 0.4 \\
\hline 10.3 & 2-Isopentyl-6-methylpyrazine & C6 & 27 & 0.2 & 52 & 0.3 & 62 & 0.4 \\
\hline 10.6 & 2,5-Dimethyl-3-isopentylpyrazine & $\mathrm{C7}$ & 24 & 0.2 & 42 & 0.3 & 76 & 0.5 \\
\hline- & Total pyrazines $(\mu \mathrm{g} / 10 \mathrm{~mL})$ & - & 11,616 & - & 15,453 & - & 15,237 & - \\
\hline - & Total mass of pyrazines $(\mathrm{g})$ & - & 0.5 & - & 0.6 & - & 0.6 & - \\
\hline- & CGF-A to total syn pyrazines mass ratio & - & 82 & - & 68 & - & 68 & - \\
\hline
\end{tabular}

Table 6. Identified pyrazine components and their mass-per-synthesis resulting from different times of the reaction (in $\mu \mathrm{g}$ ):

$\mathrm{NH}_{4} \mathrm{OH}(28 \mathrm{~mL})$, CGF-A (41 g), $0.96(\mathrm{~T}) / 0.56(\mathrm{~V}) / 0.5(\mathrm{~L}) / 0.5$ (iso-L) g; $120^{\circ} \mathrm{C}$, ramp: $1.7^{\circ} \mathrm{C} / \mathrm{min}, 30$ and $60 \mathrm{~min}$, total reaction volume: $1200 \mathrm{~mL}$, extraction conditions: $30 \mathrm{~mL}$ aliquot per $10 \mathrm{~mL} \mathrm{DCM}$.

\begin{tabular}{|c|c|c|c|c|c|c|}
\hline$R_{t}(\min )$ & Identified compound & $\mathrm{C \#}$ & $30 \min$ & $\%$ total & $60 \mathrm{~min}$ & $\%$ total \\
\hline 6.2 & Pyrazine & - & 1034 & 6.5 & 1198 & 7.0 \\
\hline 6.8 & 2-Methylpyrazine & $\mathrm{C} 1$ & 8805 & 58.0 & 8943 & 58.0 \\
\hline 7.5 & 2,5-Dimethylpyrazine & $\mathrm{C} 2$ & 1012 & 7.0 & 981 & 6.0 \\
\hline 7.6 & 2,6-Dimethylpyrazine & $\mathrm{C} 2$ & 2913 & 19.0 & 2835 & 19.0 \\
\hline 7.8 & 2,3-Dimethylpyrazine & $\mathrm{C} 2$ & 430 & 3.0 & 418 & 3.0 \\
\hline 8.1 & 2-Ethyl-6 methylpyrazine & $\mathrm{C} 3$ & 125 & 1.0 & 161 & 1.0 \\
\hline 8.2 & 2-Ethyl-5 methylpyrazine & $\mathrm{C} 3$ & 38 & 0.2 & 44 & 0.3 \\
\hline 8.4 & 2,3,5-Trimethylpyrazine & $\mathrm{C} 3$ & 530 & 3.5 & 562 & 4.0 \\
\hline 8.6 & 2-Vinylpyrazine & $\mathrm{C} 2$ & 23 & 0.1 & 18 & 0.1 \\
\hline 8.7 & 3-Ethyl-2,5-dimethylpyrazine & $\mathrm{C} 4$ & 35 & 0.2 & 63 & 0.4 \\
\hline 8.8 & 2-Methylpropylpyrazine & $\mathrm{C} 4$ & 46 & 0.3 & ND & ND \\
\hline 8.9 & 2,6-Dimethylpyrazine & $\mathrm{C} 4$ & ND & ND & 59 & 0.4 \\
\hline 9 & 2,3,5,6-Tetramethylpyrazine & $\mathrm{C} 4$ & 35 & 0.2 & 41 & 0.3 \\
\hline 9.2 & 2-Methyl-3-(2-methylpropyl) pyrazine & C5 & 20 & 0.1 & 21 & 0.1 \\
\hline 9.3 & 2,3,5-Trimethyl-6-ethylpyrazine & $\mathrm{C} 5$ & 13 & 0.1 & 21 & 0.1 \\
\hline 9.4 & 2,5-Dimethyl-3-isobutylpyrazine & C6 & 15 & 0.1 & 23 & 0.1 \\
\hline 9.8 & 2-Pentylpyrazine & $\mathrm{C} 5$ & 12 & 0.1 & 15 & 0.1 \\
\hline 9.9 & 3-Methylbutyl pyrazine & C5 & 49 & 0.3 & 52 & 0.3 \\
\hline 10.3 & 2-Isopentyl-6-methylpyrazine & C6 & 51 & 0.3 & 55 & 0.4 \\
\hline 10.6 & 2,5-Dimethyl-3-isopentylpyrazine & $\mathrm{C} 7$ & 43 & 0.3 & 57 & 0.4 \\
\hline- & Total pyrazines ( $\mu \mathrm{g} / 10 \mathrm{~mL})$ & - & 15,228 & - & 15,567 & - \\
\hline- & Total mass of pyrazines $(\mathrm{g})$ & - & 0.6 & - & 0.62 & - \\
\hline- & CGF-A to total syn pyrazines mass ratio & - & 68 & - & 66 & - \\
\hline
\end{tabular}


Table 7. Optimum synthesis conditions for microwave and Parr reactor experiments.

\begin{tabular}{lccc|c}
\hline Synthesis variable & $\mathrm{NH}_{4} \mathrm{OH}$ concentration $(\mathrm{mL})$ & Temperature $\left({ }^{\circ} \mathrm{C}\right)$ & Time $(\mathrm{min})$ & Reaction volume $(\mathrm{mL})$ \\
\hline Microwave & 28 & 120 & 30 & 240 \\
Parr & 28 & 120 & 30 & 1200 \\
\hline
\end{tabular}

Therefore, arbitrarily 30 min was chosen as the optimum time. Final optimum conditions for the previous microwave and Parr reactor studies are listed in Table 7.

\section{"Sludge" problem}

As mentioned before, the main problem in using the Parr reactor was "sludge" formation when reactions were done in reaction volumes of 240,480 , and $1000 \mathrm{~mL}$. When using microwave conditions under identical concentrations of amino acids, CGF-A, and ammonium hydroxide in reaction volumes of $240 \mathrm{~mL}$ (eight vessels, $30 \mathrm{~mL}$ each), no "sludge" was observed. While an explanation for this difference in reactivity is not obvious, several points seem worthy of consideration. Microwaves generate rapid intense heating of polar substances; while, apolar substances do not absorb the radiation and are not heated. All of the reactants in this study are polar materials that can efficiently absorb microwave energy. It seems that when using microwave these compounds become quickly activated and involved in the reaction.

Furthermore, the temperature increase should be uniform throughout the matrix which could lead to less by-products. Thus, this situation probably resulted, in pyrazine reactions without any "sludge". On the other hand, however, heat would be less efficiently conducted in the much larger Parr vessel.

Another factor concerning "sludge" formation, could possibly be the cellulosic glucose/fructose (CGF) that was used in the synthesis. According to the manufacture's data, cellulosic glucose/fructose-A mainly consists of $28 \%$ fructose and $33 \%$ glucose, and CGF-A was the sugar source used in all the syntheses reported so far in this study.

Table 8. Identified pyrazine components and their mass per synthesis resulting from use of CGF-A and CGF-B as a sugar source by means of microwave and Parr reactor (in $\mu \mathrm{g}$ ):

$\mathrm{NH}_{4} \mathrm{OH}\left(28 \mathrm{~mL}\right.$ ), CGF-B /or CGF-A (41 g), $0.96(\mathrm{~T}) / 0.56(\mathrm{~V}) / 0.5(\mathrm{~L}) / 0.5$ (iso-L) g; $120^{\circ} \mathrm{C}$ for $30 \mathrm{~min}$, ramp: $1.7^{\circ} \mathrm{C} / \mathrm{min}$, total reaction volume: microwave (CGF-A) and Parr (CGF-B): $240 \mathrm{ml}$, Parr (CGF-A): $1200 \mathrm{~mL}$; extraction conditions: $30 \mathrm{~mL}$ reaction volume per $10 \mathrm{~mL}$ of DCM.

\begin{tabular}{|c|c|c|c|c|c|c|c|c|c|c|}
\hline $\mathrm{R}_{\mathrm{t}}(\min )$ & Identified compound & C\# & $\begin{array}{c}\text { CGF-B } \\
\text { (Parr reactor) }\end{array}$ & $\begin{array}{c}\% \\
\text { total } \\
\end{array}$ & $\begin{array}{c}\text { CGF-A } \\
\text { (Parr reactor) }\end{array}$ & $\begin{array}{c}\% \\
\text { total } \\
\end{array}$ & $\begin{array}{c}\text { CGF-B } \\
\text { (microwave) }\end{array}$ & $\begin{array}{c}\% \\
\text { total } \\
\end{array}$ & $\begin{array}{c}\text { CGF-A } \\
\text { (microwave) }\end{array}$ & $\begin{array}{l}\% \\
\text { total } \\
\end{array}$ \\
\hline 6.2 & Pyrazine & & 1574 & 5.0 & 1034 & 6.5 & 2037 & 6.0 & 2565 & 6.0 \\
\hline 6.8 & 2-Methylpyrazine & $\mathrm{C} 1$ & 15,883 & 48.0 & 8,805 & 58.0 & 16,761 & 45.0 & 17,628 & 42.0 \\
\hline 7.5 & 2,5-Dimethylpyrazine & $\mathrm{C} 2$ & 2521 & 8.0 & 1012 & 7.0 & 3216 & 9.0 & 3950 & 9.0 \\
\hline 7.6 & 2,6-Dimethylpyrazine & $\mathrm{C} 2$ & 9,627 & 29.0 & 2,913 & 19.0 & 10,958 & 29.0 & 11,942 & 29.0 \\
\hline 7.8 & 2,3-Dimethylpyrazine & $\mathrm{C} 2$ & 1108 & 4.0 & 430 & 3.0 & 1328 & 4.0 & 1608 & 4.0 \\
\hline 8.1 & 2-Ethyl-6 methylpyrazine & $\mathrm{C} 3$ & 286 & 1.0 & 125 & 1.0 & 419 & 1.0 & 549 & 1.5 \\
\hline 8.2 & 2-Ethyl-5 methylpyrazine & C3 & 65 & 0.2 & 38 & 0.2 & 93 & 0.2 & 119 & 0.3 \\
\hline 8.4 & 2,3,5-Trimethylpyrazine & $\mathrm{C} 3$ & 1300 & 4.0 & 530 & 3.5 & 1708 & 5.0 & 2095 & 5.0 \\
\hline 8.6 & 2-Vinylpyrazine & $\mathrm{C} 2$ & 35 & 0.1 & 23 & 0.1 & 73 & 0.2 & 97 & 0.2 \\
\hline 8.7 & 3-Ethyl-2,5-dimethylpyrazine & $\mathrm{C} 4$ & 60 & 0.2 & 35 & 0.2 & 82 & 0.2 & 108 & 0.3 \\
\hline 8.8 & 2-Methylpropylpyrazine & $\mathrm{C} 4$ & ND & ND & 46 & 0.3 & ND & ND & ND & - \\
\hline 8.9 & 2,6-Dimethyl-3-ethylpyrazine & $\mathrm{C} 4$ & 72 & 0.2 & ND & ND & 112 & 0.3 & 136 & 0.3 \\
\hline 9 & 2,3,5,6-Tetramethylpyrazine & $\mathrm{C} 4$ & 54 & 0.2 & 35 & 0.2 & 84 & 0.2 & 113 & 0.3 \\
\hline 9.2 & $\begin{array}{l}\text { 2-Methyl-3-(2-methylpropyl) } \\
\text { pyrazine }\end{array}$ & C5 & 54 & 0.2 & 20 & 0.1 & 65 & 0.2 & ND & - \\
\hline 9.3 & $\begin{array}{l}\text { 2,3,5-Trimethyl-6- } \\
\text { ethylpyrazine }\end{array}$ & C5 & ND & ND & 13 & 0.1 & ND & ND & 32 & 0.1 \\
\hline 9.4 & $\begin{array}{l}\text { 2,5-Dimethyl-3- } \\
\text { isobutylpyrazine }\end{array}$ & $\mathrm{C} 6$ & 41 & 0.1 & 15 & 0.1 & 52 & 0.1 & 64 & 0.2 \\
\hline 9.8 & 2-Pentylpyrazine & $\mathrm{C} 5$ & 69 & 0.2 & 12 & 0.1 & 54 & 0.1 & 83 & 0.2 \\
\hline 10 & 3-Methylbutylpyrazine & C5 & 274 & 1.0 & 49 & 0.3 & 245 & 1.0 & 360 & 0.9 \\
\hline 10.3 & $\begin{array}{l}\text { 2-Isopentyl-6- } \\
\text { methylpyrazine }\end{array}$ & $\mathrm{C} 6$ & 176 & 0.5 & 51 & 0.3 & 174 & 0.5 & 261 & 0.6 \\
\hline 10.5 & $\begin{array}{l}2,5 \text {-Dimethyl-3- } \\
\text { isopentylpyrazine }\end{array}$ & $\mathrm{C} 7$ & 133 & 0.4 & 43 & 0.3 & 133 & 0.4 & ND & - \\
\hline 10.6 & 2,6-Dimethyl-3-butylpyrazine & $\mathrm{C} 7$ & ND & - & ND & - & ND & - & 147 & 0.4 \\
\hline- & Total pyrazines $(\mu \mathrm{g} / 10 \mathrm{~mL})$ & - & 33,332 & - & 15,228 & - & 37,594 & - & 41,860 & - \\
\hline- & Total mass of pyrazines $(\mathrm{g})$ & - & 1.3 & - & 0.6 & - & 0.3 & - & 0.34 & - \\
\hline- & $\begin{array}{l}\text { CGF-(A/B) to total syn } \\
\text { pyrazines mass ratio }\end{array}$ & - & 32 & - & 68 & - & 137 & - & 120 & - \\
\hline
\end{tabular}


Preliminary experiments on the other hand using cellulosic glucose/fructose-B, with $42 \%$ fructose and $50 \%$ glucose as an alternative sugar source for pyrazine synthesis, showed that by using $41 \mathrm{~g}$ of CGF-B, $0.96 \mathrm{~g}$ threonine (T), $0.56 \mathrm{~g}$ valine $(\mathrm{V}), 0.5 \mathrm{~g}$ L-leucine $(\mathrm{L})$ and $0.5 \mathrm{~g}$ L-isoleucine (iso$\mathrm{L}$ ), and $28 \mathrm{~mL}$ of $30 \% \mathrm{NH}_{4} \mathrm{OH}$ at $120{ }^{\circ} \mathrm{C}$ for $30 \mathrm{~min}$ and a total reaction volume of $240 \mathrm{~mL}$, in both microwave and Parr reactor experiments, no "sludge" was observed via either heating regimen.

See Table 8 for a comparison between the individual identified pyrazine components and their mass per synthesis resulting from use of CGF-A and CGF-B as a sugar source by means of microwave and Parr reactor. Microwave conditions gave lower combined percentages of the total for (pyz+2-met) than Parr. In terms of selectivity, both CGF-A and CGF-B yielded similar results. When the data in Table 8 were analyzed in terms of mass of sugar substitute per mass of total synthesized pyrazines, considerably more sugar was required for comparable pyrazine yields of one over the other. If one examines all seven tables in this report, the ratio is uniformly higher for microwave (greater than 100) than for Parr (less than 100).

Another point is worth making here. Fructose is known to be the active ingredient in both CGF-B and CGF-A. Since the amount of fructose in CGF-B is higher than CGF-A, this could be the reason that reactions without any "sludge" problem are favored when using CGF-B. Alternatively, spiking with only pure fructose should result in less "sludge" formation.
An alternate possible solution to the "sludge" issue might be to use more of the cellulosic glucose/fructose (i.e., change the fructose/glucose nitrogen ratio). The results of the experiments employing this approach have shown this method to be an ineffective strategy. This is due to the fact that by increasing the concentration of CGF-A, the amount of glucose and fructose will also increase and unreacted glucose could be the cause of more "sludge" formation.

Yet, another possibility for addressing this problem would be to spike more fructose to the original CGF-A.

For testing this idea, $0.1 \mathrm{M}$ fructose was added to $41 \mathrm{~g}$ of CGF-A along with the same reactants described previously. This synthesis approach unfortunately resulted in "sludge" formation. In a separate synthesis, the amount of fructose was significantly increased to $0.5 \mathrm{M}$ fructose under the same reaction conditions. As predicted no "sludge" was observed (Table 9). Alternate solutions to the "sludge" issue could be addition of excess CGF-A which has a relatively higher content of fructose, or possibly isolate the fructose from the CGF-A mixture and using it as the sole carbon source.

Another observation arising from this study was to reduce the amino acid concentration by dilution of the reactants with additional water since it seems that the amino acid concentration maybe a dominate factor influencing the "sludge" problem.

Table 9. Identified pyrazine compounds after increasing the amount of fructose to $0.5 \mathrm{M}$ :

$\mathrm{NH}_{4} \mathrm{OH}(28 \mathrm{~mL})$, CGF-A $(41 \mathrm{~g}), 0.96(\mathrm{~T}) / 0.56(\mathrm{~V}) / 0.5(\mathrm{~L}) / 0.5$ (iso-L) g; temperature: $120^{\circ} \mathrm{C}$ for $30 \mathrm{~min}$, ramp: $1.7^{\circ} \mathrm{C} / \mathrm{min}$, total reaction volume: $1200 \mathrm{~mL}$, extraction conditions: $30 \mathrm{~mL}$ aliquot per $10 \mathrm{~mL}$ DCM.

\begin{tabular}{|c|c|c|c|c|}
\hline $\mathrm{R}_{\mathrm{t}}(\min )$ & Identified compound & $\mathrm{C} \#$ & Fructose $(0.5 \mathrm{M})$ & $\%$ total \\
\hline 6.2 & Pyrazine & & 1249 & 5.0 \\
\hline 6.8 & 2-Methylpyrazine & $\mathrm{C} 1$ & 14,633 & 50.0 \\
\hline 7.5 & 2,5-Dimethylpyrazine & $\mathrm{C} 2$ & 2496 & 8.5 \\
\hline 7.6 & 2,6-Dimethylpyrazine & $\mathrm{C} 2$ & 8900 & 30.0 \\
\hline 7.8 & 2,3-Dimethylpyrazine & $\mathrm{C} 2$ & 1048 & 3.0 \\
\hline 8.1 & 2-Ethyl-6 methylpyrazine & $\mathrm{C} 3$ & 131 & 0.5 \\
\hline 8.2 & 2-Ethyl-5 methylpyrazine & $\mathrm{C} 3$ & 33 & 0.1 \\
\hline 8.37 & 2,3,5-Trimethylpyrazine & $\mathrm{C} 3$ & 649 & 3.0 \\
\hline 8.6 & 2-Vinylpyrazine & $\mathrm{C} 2$ & 50 & 0.2 \\
\hline 8.7 & 3-Ethyl-2,5-dimethylpyrazine & $\mathrm{C} 4$ & 27 & 0.1 \\
\hline 8.8 & 2-Methylpropylpyrazine & $\mathrm{C} 4$ & ND & ND \\
\hline 8.9 & 2,6-Diethylpyrazine & $\mathrm{C} 4$ & 36 & 0.1 \\
\hline 9 & 2,3,5,6-Tetramethylpyrazine & $\mathrm{C} 4$ & 22 & 0.1 \\
\hline 9.2 & 2-Methyl-3-(2-methylpropyl) pyrazine & $\mathrm{C} 5$ & 24 & 0.1 \\
\hline 9.3 & 2,3,5-Trimethyl-6-ethylpyrazine & C5 & ND & ND \\
\hline 9.4 & 2,5-Dimethyl-3-isobutylpyrazine & $\mathrm{C} 6$ & 15 & 0.1 \\
\hline 9.8 & 2-Pentylpyrazine & C5 & 16 & 0.1 \\
\hline 9.9 & 3-Methylbutylpyrazine & C5 & 66 & 0.3 \\
\hline 10.3 & 2-Isopentyl-6-methylpyrazine & $\mathrm{C} 6$ & 24 & 0.1 \\
\hline 10.6 & 2,5-Dimethyl-3-isopentylpyrazine & $\mathrm{C} 7$ & 45 & 0.2 \\
\hline- & Pyrazines per extraction $(\mu \mathrm{g})$ & - & 29,463 & - \\
\hline - & Pyrazines per total reaction $(\mathrm{g})$ & - & 1.2 & - \\
\hline- & CGF-A to total syn pyrazines mass ratio & - & 34 & - \\
\hline
\end{tabular}




\section{CONCLUSIONS}

According to this study, by using a) cellulosic glucose/fructose mixture as a cellulosic sugar source and b) a mixture of four amino acids, L-leucine, L-isoleucine, Lthreonine and L-valine, plus c) $\mathrm{NH}_{4} \mathrm{OH}$, a series of C1-C7 branched pyrazines in aqueous formulations was produced. Comparing the results obtained here with those presented in our previous paper (7) using a traditional open-heated oil bath method for pyrazine synthesis, the yield of synthesized pyrazines increased dramatically, with the Parr reactor system outperforming the yield via microwave. Nearly $80 \%$ of the total yield for both methods was $\mathrm{C} 1 / \mathrm{C} 2$ methylpyrazines including 2-methylpyrazine, 2,5-dimethylpyrazine, 2,6-dimethylpyrazine, and 2,3-dimethylpyrazine. The remaining pyrazines were each less than $2 \%$ of the total except for 2,3,5-trimethylpyrazine which was $4-6 \%$ of the total. The main issue/problem regarding the pyrazine synthesis was the gummy (or refractory) brownish substance that was termed "sludge". To address the "sludge" problem, different experiments were performed whereby the concentration of reactants for synthesis of pyrazines using microwave and Parr reactor were optimized. Due to the nature of microwave energy which can penetrate throughout the sample uniformly, this technique was predicted to lead to less by-products or decomposition products and higher pyrazines yields as compared to techniques using traditional heat transfer equipment such as oil baths, sand baths and heating jackets. However this assumption proved to be untrue since the Parr reactor gave higher pyrazine yields.

\section{ACKNOWLEDGEMENT}

This research was supported by a monetary gift from R.J. Reynolds Tobacco Company. Dr. Katayoun Mahdavi Ara was selected as an RJRT-Harold McNair Postdoctoral Fellow in 2015-16.

\section{REFERENCES}

1. Loupy, A. and A. de la Hoz (ed.): Microwaves in Organic Synthesis; Wiley-VCH, Weinheim, Germany, 2002. ISBN: 978-3-527-33116-1

2. Bogdal, D., P. Penczek, J. Pielichowski, and A. Prociak: Microwave Assisted Synthesis, Crosslinking and Processing of Polymeric Materials; Adv. Polym. Sci 163 (2003) 193-263. DOI: 10.1007/b11051

3. Lidström, P., J. Tierney, B. Wathey, and J. Westman: Microwave Assisted Organic Synthesis - A Review; Tetrahedron 57 (2001) 9225-9283. DOI: $10.1016 /$ S0040-4020(01)00906-1

4. Coleman III, W.M. and T.J. Steichen: Sugar and Selected Amino Acid Influences on the Structure of Pyrazines in Microwave Heat-Treated Formulations; J. Sci. Food Agric. 86 (2006) 380-391. DOI: $10.1002 /$ jsfa. 2363

5. Coleman III, W.M. and T.A. Perfetti: The Roles of Amino Acids and Sugars in the Production of Volatile Materials in Microwave Heated Tobacco Dust Suspensions; Beitr. Tabakforsch. Int. 17 (1997) 75-95. DOI: $10.2478 /$ cttr-2013-0660

6. Coleman III, W.M.: On the Synthesis and Characteristics of Aqueous Formulations Rich in Pyrazines. Flavor, Fragrance, and Odor Analysis; ed. by R. Marsili, CRC Press, Boca Raton, FL, 2012, pp. 135-181.

7. Ara, K.M., L.T. Taylor, M. Ashraf-Khorassani, and W.M. Coleman III: Alkyl Pyrazine Synthesis via an Open Heated Bath with Variable Sugars, Ammonia, and Various Amino Acids; J Sci Food Agric. 97 (2017) 2263-2270. DOI: 10.1002/JSFA.8039.

Corresponding author:

Prof. Larry T. Taylor

Department of Chemistry, Viginia Tech

Blacksburg, VA 24061-0212, USA

E-mail: ltaylor@vt.edu 